\title{
Study on Influence of Cooling Mode on the Permeability of High Temperature Damaged Concrete
}

\author{
Qing $\mathrm{Su}^{*}$ and Kunfa Li \\ Wuchang University of technology, Wuhan, China \\ *Corresponding author
}

\begin{abstract}
Two experiments of capillary suction and chloride penetration were carried out on the concrete specimens after exposure to natural cooling and spray water-cooling, and absorption coefficient and permeability coefficient were used to estimate the combining influence of cooling mode and temperature. The results show that high temperature cause severe degradation both the capillary suction and chloride ion resistance of concrete. Owing to short spray cooling time, the large temperature difference between inside and outside of concrete and large temperature stress, which accelerate progressive ion penetrating from outside. Then water absorption coefficient and chloride ion content in concrete surface is significantly greater than that of exposure to natural cooling. Therefore, spray water cooling mode has worse effect on permeability of concrete damaged in high temperature.
\end{abstract}

Keywords-component; cooling mode; after exposure to high temperature; penetration coefficient

\section{INTRODUCTION}

In firing, the building materials should resist high temperature, which will ensure the infrastructure not only has enough bearing capacity and stability under high temperature, but also still has the value of continue to use after maintenance, all benefit to ensure maximum safety of life and reduce economic loss. However, the research on long-term performance and durability of concrete after high temperature is few and the influence of spray water-cooling on the concrete is less considered in previous studies. Actually, in repairing of reinforced concrete structure, more attentions have been paid on the low temperature regions. And only methods of cleaning concrete surface, filling and grouting have carried out. Furthermore, bearing capacity and stability of concrete has been emphasized in repairing scheme, ignoring the effect of high temperature on the durability of concrete structures, and the old concrete damaged under high temperature still retained.Some of researchs[1-2] show that the deteriorartion degree of durability of concrete material is more significant than machanical behavior. When exposed in salt frog, concrete resistance to chloride ion erosion ability obviously decreased with the rise of temperature, and high temperature affect the performance of concrete durability than strength [3]. The fact that with the increase of temperarture, the resistance of acid, alkaline of aritifical sand concrete decreases greatly, and especially the former, has been prescribed by Jiang [4].

In this paper, the influence of temperature and cooling mode on the permeability of concrete has been discussed.The immersion experiments were carried out on the high temperature demaged concrete with water/cement ratio of 0.4 and 0.5 , after natural cooling and water cooling process. And the permeability coefficient was used for analysising, which will provied necessary data for maintenance of high temperature damaged concrete structures.

\section{EXPERIMENTAL}

\section{A. Specimens and Curing}

Two groups of concrete with water/cement ratio 0.4 and 0.5 have been prepared for test. The raw materials include, Crushed aggregates with size ranging in $5 \sim 25 \mathrm{~mm}$ and river sand with fineness modulus of 2.6 have been used as aggregate. Chinese Ordinary Portland Cement P.O42.5 has been selected for this project. The poly carboxylic acid has used as water reducing agent. The exact composition of the concrete is given in Table I.The prepared concrete has been poured into cubic mould with $100 \mathrm{~mm}$ edge length. After two days, they have been demoulded and then stored in standard curing room until age of $28 \mathrm{~d}$.

TABLE I. THE COMPOSITION OFCONCRETE $\left(\mathrm{kg} / \mathrm{m}^{3}\right)$

\begin{tabular}{|l|l|l|l|l|l|l|}
\hline Group & Cement & Sand & Gravel & Water & $\begin{array}{c}\text { Water } \\
\text { reducer }\end{array}$ & W/B \\
\hline C1 & 380 & 579.1 & 1269 & 152 & 4.95 & 0.4 \\
\hline $\mathrm{C} 2$ & 320 & 653 & 1267 & 160 & 3.82 & 0.5 \\
\hline
\end{tabular}

\section{B. Heating and Cooling Experiments}

In order to prevent cracking under high humidity, the concrete cube will be placed in the thermostatic chamber (temperature $20^{\circ} \mathrm{C}$, humidity $50 \%$ ) for $5 \mathrm{~d}$ after curing. The high temperature electric resistance furnace with temperature controlling device has used for heating. The rate of temperature increasing has been set at $5^{\circ} \mathrm{C} / \mathrm{min}$ till to the target temperature and keep for $3 \mathrm{~h}$, which ensure uniform temperature inside the specimen. In order to analyze the influence of temperature, the target temperature was set at $100^{\circ} \mathrm{C}$ to $600^{\circ} \mathrm{C}$ with $100^{\circ} \mathrm{C}$ interval.

With the increasing of heating temperature, the concrete blocks appear colour changes. Compared with specimens exposed in normal, the specimens seem as no obvious crack under temperature of $100^{\circ} \mathrm{C}, 200^{\circ} \mathrm{C}$ and $300^{\circ} \mathrm{C}$. Then, block surface show pink with small cracks after $400^{\circ} \mathrm{C}$. When temperature increase over $500{ }^{\circ} \mathrm{C}$, block surface pale and crack 
obviously. At last, block fracture with much wide cracks when the temperature rises to $600^{\circ} \mathrm{C}$.

After heating and keeping for $3 \mathrm{~h}$, the natural cooling (A) and spray water cooling (W) will be carried out respectively. Natural cooling scheme is that the block wiil be placed indoor. The scheme of spraying water on the block surface and cooling it quickly is water-cooling.

\section{Permeability Tests}

After heating and cooling, capillary suction and chloride penetration test have been carried out on the concrete block, respectively.

Capillary suction test has been measured by standard method [5] and device is shown in Figure I. In this case the concrete cubes are placed in direct contact with water and the water absorbed by capillary suction is measured by weighing the specimens after maximum duration of contact of 72 hours. The sample result obtained is shown in Figure.1, in which the points are average values of at least three independent measurements. The further results are listed in Table II.

TABLE II COEFFICIENT OF CAPILLARY SUCTION A OF CONCRETE WITH DIFFERENT COOLING MODE VALUES OF AARE GIVEN IN $\left(\mathrm{g} /\left(\mathrm{m}^{2} \mathrm{~h}^{1 / 2}\right)\right)$

\begin{tabular}{|l|l|l|l|l|}
\hline \multirow{2}{*}{$\begin{array}{c}\text { Temperature/ } \\
\text { C }\end{array}$} & \multicolumn{2}{|c|}{ C1 } & \multicolumn{2}{c|}{ C2 } \\
\cline { 2 - 5 } & $\boldsymbol{A}$ & $\boldsymbol{W}$ & \multicolumn{1}{c|}{$\boldsymbol{A}$} & $\boldsymbol{W}$ \\
\hline 600 & 7216.02 & 7426.04 & 6883.41 & 8284.43 \\
\hline 500 & 2777.46 & 2967.45 & 2797.82 & 2997.88 \\
\hline 400 & 1898.67 & 1670.13 & 1584.11 & 1601.77 \\
\hline 300 & 1150.55 & 1128.83 & 714.55 & 1023.32 \\
\hline 200 & 888.87 & 891.94 & 606.30 & 646.28 \\
\hline 100 & 507.65 & 515.33 & 735.92 & 503.14 \\
\hline 20 & 412.33 & 412.33 & 578.91 & 578.91 \\
\hline
\end{tabular}

A simple equation can be deduced theoretically to describe capillary absorption as function of time as a first approximantion. In equation (1) $\Delta \mathrm{W}$ stands for the amount of water absorbed by capillary suction perunit of contact surface $S$ as function of the duration of contact:

$$
\Delta \mathrm{W}=B \sqrt{t}
$$

B is the coefficient of capillary suction. From Figure II, it can be seen that equation (1) describes the time dependence of capillary suction of concrete reasonable well within the duration of contact under investigation. The coefficient of capillary suction B characterizes the capillary water uptake by the porous structure of different types of conrete. Values of B as obtained from the experimental results by linerar regression are compiled in Table II.

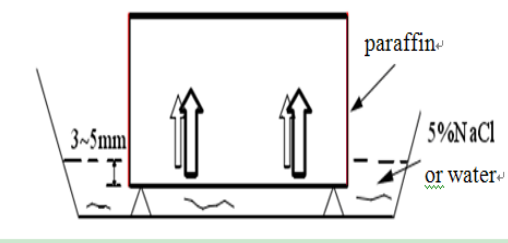

FIGURE I. SCHEMATIC OF PERMEABILITY TEST

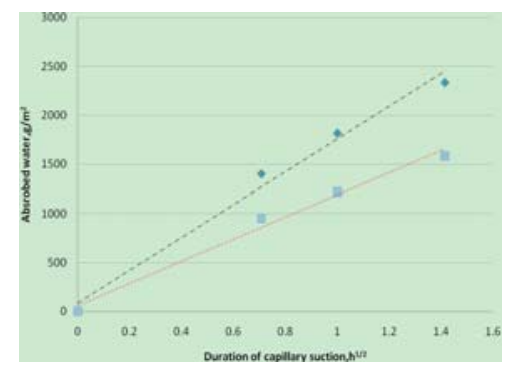

FIGURE II. WATER UP-TAKE BY CAPILLARY SUCTION OF DAMAGED CONCRETE

For reference to capillary suction test, the concrete specimens have been immersed in $5 \% \mathrm{NaCl}$ for $7 \mathrm{~d}$ and dried to constant weight. The quantity and distribution of chloride will been determined by a more sophisitcated method. From the concrete specimens layers parallel to the initial moulded surface and having a thickness of $2 \mathrm{~mm}$ each have been milled by means of a specially built diamond milling cutter consecutively, shown in Figure III. The powder obtained from this process was collected in small plastic bags. Later the chloride ion content of these powder samples has been determined by method in [5]. In this way, the chloride profiles have been measured directly.

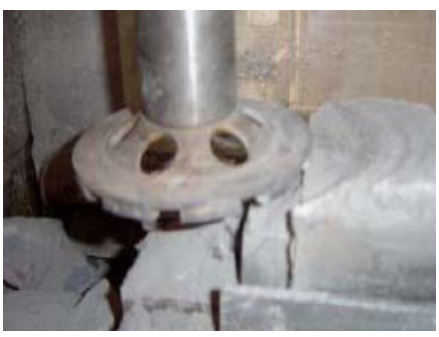

FIGURE III. MILLING CUTTER

\section{RESULTS AND DISCUSSION}

\section{A. The Effects of Cooling Mode on Weight}

The influence of high temperature and cooling mode on the weight loss of concrete specimens is shown histogram as Figure IV. 


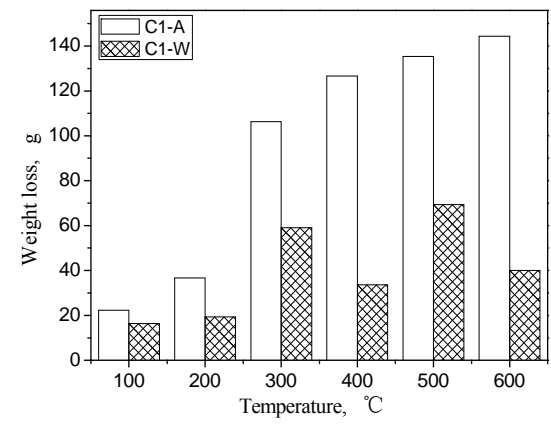

(a) $\mathrm{Cl}$

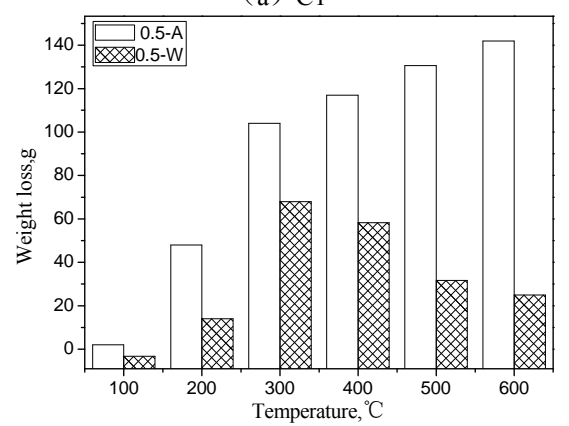

(b) $\mathrm{C} 2$

FIGURE IV. THE INFLUENCE OF COOLING MODE ON THE WEIGHT LOSS OF DAMAGED CONCRETE

It can be seen from Figure IV that the weight loss increase with the temperature rise, and the influence of natural cooling is much obvious than that of spray cooling. When exposed to $100^{\circ} \mathrm{C}$, the weight loss of concrete has been rose by free water evaporation in pore. With temperature rising to $400^{\circ} \mathrm{C}$, the fact that free water evaporate and bound water escape cause further loss. The C-S-H gel begins to resolve. Next, when the temperature rise to $600^{\circ} \mathrm{C}$, the water bound in and between $\mathrm{C}$ $\mathrm{S}-\mathrm{H}$ gel escape significantly, the $\mathrm{Ca}(\mathrm{OH}) 2$ decomposes, and cracks occure and develope gradually. Under the pressure induced by water-cooling, water penetrate into the concrete quickly, which weak the weight loss owing to gel water overflow in some extent [6-11]. Nevertheless, this mechanism also can be explained as that the concrete damaged possess good water absorbing capacity and benefit the penetration of progressive ions from outside, which harm the durability of structures damaged in high temperature.

\section{B. The Effects of Cooling mode on Capillary Suction of Concrete Damaged}

According to 1.3 , the B regressed are compiled in Table II and shown in histogram as Figure V. The maximum unit water quantity of concrete damaged in high temperature is paint in Figure VI.

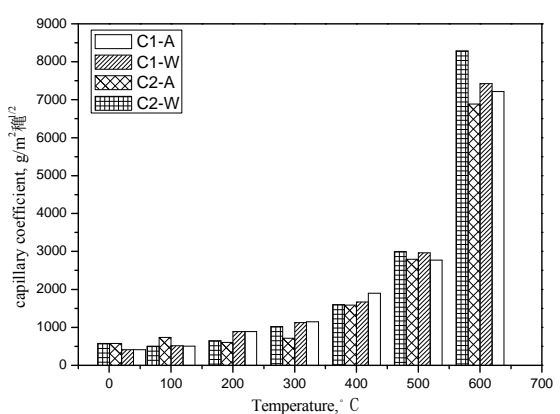

FIGURE V. CAPILLARY COEFFICIENT OF CONCRETE

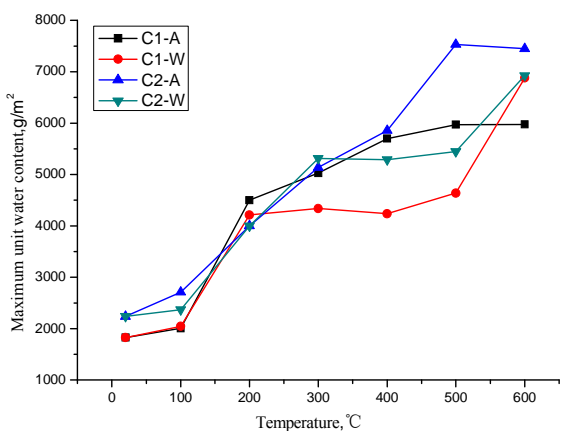

FIGURE VI. THE MAXIMUM UNIT WATER QUANTITY OF DAMAGED CONCRETE

It can be seen from Figure $V$ that with increasing of heating temperature, the influence of water-cooling on the capillary coefficient is much bigger than that of natural cooling, which concide with the concrete loss. The reason may be that the spray accelerates the degradation of concrete. In Figure VI, the conclusion that the maximum unit water quantity of spray cooling block is less than natural cooling is not conform to the facts that the concrete will be damaged more seriously exposed to spray cooling [12]. The reason may be explained as that spraying time is shorter and the damage mainly produced in surface concrete, the internal temperature reduce quickly and effect is relatively small. However, the rate and coefficient of capillary suction has intimate relationship with pore structure and porosity of surface concrete, the maximum unit water quantity only has relationship with total porosity of concrete, which of spray cooling concrete is less than that of natural cooling, then the water quantity of former is smaller.

Compared with $\mathrm{C} 2$ concrete, the maximum unit water quantity of $\mathrm{C} 1$ is less and the anti-permeability is much better owing to more denser and low porosity.

\section{The Effects of Cooling Mode on Chloride Permeability}

The chloride profiles of $\mathrm{C} 1$ concret after different cooling mode have been curved in Figure VII. 


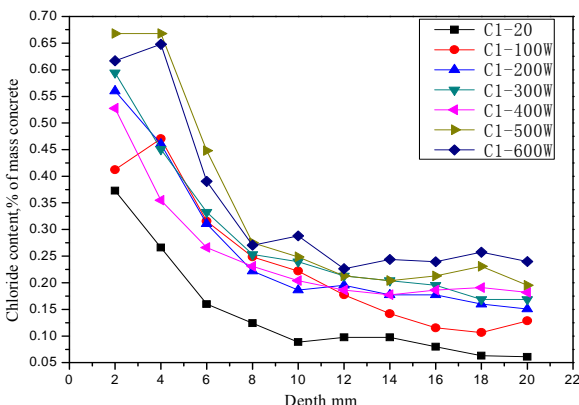

(a) spray cooling

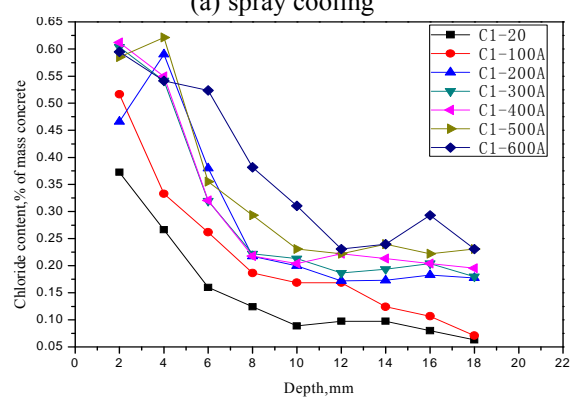

(b) natural cooling

FIGUREVII. THE CHLORIDE PROFILE OF C1 CONCRETE

After serious treatment of heating and contact with 5\% sodium chloride solution for $7 \mathrm{~d}$, the relaiton between chloride content and penetration depth has been shown in Figure VI. Compared with concrete block without heating, the chloride resistance of damaged concrete degrades severely and chloride ion penetrates deeper. For concrete block without heating, the chloride initial concentration is $0.07 \%$ (quality content), this value increased double after exposure in $200^{\circ} \mathrm{C}$. As for penetration depth, the concrete damaged in $100^{\circ} \mathrm{C}$ and then spray cooling, the depth is more than $20 \mathrm{~mm}$, which approximates the concrete damaged in $100^{\circ} \mathrm{C}$ with natural cooling. Thus, the chloride ion content of concrete with spray cooling is higher than that of natural cooling ones. The reason may be that, the surface zone of concrete has been seriously damaged in spray cooling, which accelerates capillary absorption of sodium chloride solution and more chloride ion penetrates. The temperature of surface concrete plunges and form obvious temperature difference between inside and outside in water-cooling, resulting in larger temperature stress, then cracks. In addition, the process of spray cooling greatly stimulate the power of progressive ions penetrating into the concrete, which work together with the high internal temperature, the moisture evaporate quickly ,vapor pressure increase and internal pore structure deteriorate further[13, 14].

\section{CONCLUSION}

It has been shown that the cooling mode greatly affects the durability of concrete damaged in high temperature.The results indicate that compared with concrete with natural cooling, the chloride content of concrete exposed in $200^{\circ} \mathrm{C} \sim 400^{\circ} \mathrm{C}$ and water-cooling have multiplied. The microstructure of surface concrete is more serious damaged in high pressure produced in spray water-cooling, which harm the durability of concrete further. Thus, not only the bearing capacity and stability, but also durability of concrete structure shoulde be pay close attention in repair and retrofit.

\section{ACKNOWLEDGMENT}

The author of this contribution gratefully acknowledge substantial support of this project by Educational Department of Hubei Province (Contract No: B2017323).

\section{REFERENCES}

[1] Ma Zhi-ming, Zhao Tie-jun, Liu Zhi-qiang. Study on influence of high temperature damage and cooling mode on permeability of conrete structure[C].China Building Waterproof, 2013, 24.

[2] Bazant Z P,Kaplan M F.Concrete and high temperature[M].London, Longman Group Limited,1996.

[3] Jiang Fu-xiang, Zhao Tie-jun, Su Qing. Anti-chloride penetration and water repellent treatment of concrete after fire[J]. Concrete,2009,8, pp.:40-42.

[4] Chen Zheng-fa, Liu Gui-feng, Xu Jian-min..Study on the strength and durability with manufactured-sand under condition of high temperature[J]. Concrete, 2011,10, pp. 46-48.

[5] ISO 15148. Hygrothermal performance of building materials and products - Determination of water absorption coefficient by partial immersion.

[6] Fen Nai-qian, Xing feng. Durabiligy of Concrete [M]. 2009.

[7] Tao Jin, Liu Xian, Yuan Yong. Transient strain of self-compacting conrete at high temperature[J].Journal of Building Materials, 2009, 12(1), pp. 47-51.

[8] Wang Peng-gang. Research on the influence of high temperature on the silica repellent [D].Qingdao University of Technology, 2010.

[9] Liu Zhi-qiang, Zhao Tie-jun, Wang Peng-gang..Experimental study of ultrasonic messurement on cement based materials after exposure to elevated temperature [J].Concrete, 2012(9) pp. 6-8.

[10] Wang Hai-long, Yu Qiu-jia, Sun Xiao-yan. Durability and damage evaluation of concrete subjected to high temperature $[\mathrm{J}]$. Journal of Jiangsu University: Natural Science Edition, 2014(2) pp. 238-242.

[11] Lu Tian-qi, Zhao Guo-fan, Lin Zhi-shen.Microscopic analysis of long standing concrete after high temperature[J]. Journal of Building Materials, 2003,6(2) pp. 135-141.

[12] Zi Wei, Yu Zhi-wu, Kuang Ya-zhou.Influences of fire temperature and time on concrete residual compressive strength after water cooling[J].Journal of Central South University, 2013, 44, pp. 1545-1549.

[13] Bai Liang, Zhou Tian-hua, Lv Jin. Compressive Strength Study and Microsopic Analysis of Multi-aged Exising Concrete After High Temperature[J].Journal of arichitecture and civil engineering, 2014(4) pp. 46-50.

[14] Chen Xiao-ting, Zhao Ren-da. Experimental research of effects of high temperature on the porosity and permeability of concrete[J].China Concrete and cement products, 2007,2 pp. 11-16. 